\title{
openheart Artificial intelligence and machine learning: the resurgence of the industrial revolution by robots
}

\author{
Manal Alasnag, ${ }^{1}$ Yasmin Hanfi (D) ${ }^{2}$ Mirvat Alasnag (D) ${ }^{3}$
}

To cite: Alasnag M, Hanfi Y, Alasnag M. Artificial intelligence and machine learning: the resurgence of the industrial revolution by robots. Open Heart 2022;9:e001883. doi:10.1136/ openhrt-2021-001883

Accepted 31 December 2021

\section{SLinked}

- http://dx.doi.org/10.1136/ openhrt-2021-001802

- http://dx.doi.org/10.1136/ openhrt-2021-001832

Check for updates

C) Author(s) (or their employer(s)) 2022. Re-use permitted under CC BY-NC. No commercial re-use. See rights and permissions. Published by BMJ.

${ }^{1}$ Evelina London Children's Hospital, St Thomas' Hospital, London, UK

${ }^{2}$ Cardiology, Dallah Hospital, Riyadh, Saudi Arabia

${ }^{3}$ Cardiac Center, King Fahd Armed Forces Hospital, Jeddah, Saudi Arabia

Correspondence to Dr Manal Alasnag; manal. alasnag@gstt.nhs.uk
Human beings have always resisted change which stems from fear. In 1760, we feared the industrial revolution would replace our jobs. A t that time, as technological and scientific advances unfolded, it quickly became apparent that industrialisation permitted mass production, consistent quality and timely delivery for a growing population. Ultimately, it generated jobs. Today, we encounter similar reservations revolving around artificial intelligence (AI) and machine learning (ML). There is concern it will replace physicians. On closer inspection, both AI and ML will enable practitioners to streamline and tailor patient care, allowing for more efficacious, facile and individualised preventive measures for the population at large (figure 1).

In their article, Sarraju et al describe a model designed to further risk stratify individuals of multiethnic origins with established atherosclerotic cardiovascular disease (ASCVD). ${ }^{1}$ Data were extracted from the electronic health record. Logistic regression reported the Thrombolysis in Myocardial Infarction Risk Score for Secondary Prevention (TRS $2^{\circ} \mathrm{P}$ ) from the area under the curve of the gradient boosted models (XGBoost). Interestingly, they included women, Asians, Caucasians and Hispanic populations from a pool of 32192 of whom 23475 had ASCVD. At 5 years of follow-up, 4010 patients (12.5\%) sustained a new ASCVD event. The ML model outperformed the standard TRS $2^{\circ} \mathrm{P}$ risk scoring. In addition to the conventional risk factors, the variables with the highest predictable value determined by XGBoost included prior ASCVD and non-traditional risk factors, like education and socioeconomic levels. Similarly, other ML studies (Reduction of Atherothrombosis for Continued Health and Second Manifestations of Arterial Disease) reported consistent performance throughout the cohort in weeding out residual risk in those with established cardiovascular diseases. $^{2}{ }^{3}$ Nevertheless, it is essential to recognise the limitation of these models in younger lower-risk populations without prior ASCVD.

Factoring age into algorithms is consistently challenging, particularly as we recognise the value of lifetime risk reduction in preventive therapies. Jonas et al performed a post hoc analysis of 303 patients from the CREDENCE trial referred for coronary angiography followed by cardiac CT (CCTA). ${ }^{4}$ This analysis was blinded, and core lab was adjudicated. Using quantitative coronary angiography, obstructive $(>50 \%)$ or non-obstructive $(<50 \%)$ lesions were stratified. In addition, AI software quantified plaque volume (PV), low-density non-calcified plaque (LD-NCP), non-calcified plaque (NCP), calcified plaque $(\mathrm{CP})$, lesion length from the CCTA images. AI was able to characterise the obstructive disease and non-obstructive disease and report the results by age. Patients older than 65 years were more likely to have CP. Younger patients had more \%PAV (LD-NCP) $(1.5 \%$ vs $0.7 \%, \mathrm{p}<0.038)$. Younger patients had more PV, LD-NCP, NCP and longer lesions in obstructive disease than a non-obstructive disease. Understanding disease patterns permits the selection of appropriate invasive strategies for obstructive lesions and intensifying preventive strategies often neglected in younger patients. Figure 2 summarises the trials reporting patterns of atherosclerosis in different subsets.

There are examples of successful clinical applications of AI across many disciplines. Although D'Costa and Zatale ${ }^{6}$ focus on the role of $\mathrm{AI}$ in the discipline of cardiology, they present a brief introduction to AI principles and a sound, concise overview. The concept of deep learning (DL) is compared with how we as humans think by using our 'neural network.' Going beyond the use of algorithms, data input is processed through multiple layers, each consisting of algorithms that produce output that is processed further. 


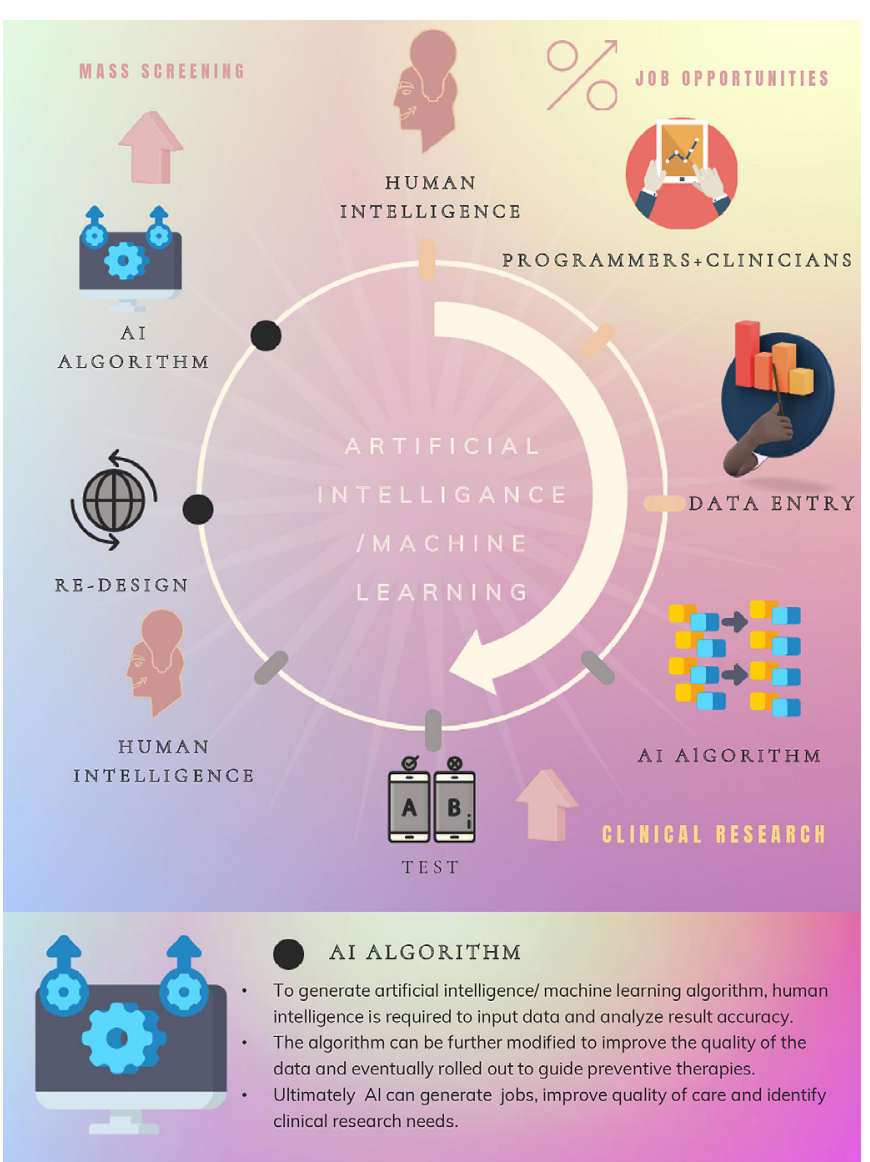

Figure 1 Central illustration and the utility of $\mathrm{Al}$ and machine learning in medicine. Al, artificial intelligence.

DL is clinically applied to detect and classify arrhythmias. Furthermore, the advancement in natural language processing means that information is now extracted from clinical notes, imaging reports, laboratory results and real-time vital signs. This pool of data is the basis of AI application in critical care predictive analytics. Forecasting patient deterioration with multidimensional algorithms allows clinicians to identify risk and undertake interventions with the possibility of changing the course of the disease. With the advent of ML, predictive patient trajectory models prove more accurate than early warning scores, which lack specificity. For example, ML models can generate more precise predictions in central line-associated bloodstream infections, which infection control experts use to tailor management for high-risk patients. AI is also used in specialised critical care units such as neurointensive care to predict seizures. AI helps identify patients expected to require prolonged respiratory support, so management, including the timing of tracheostomy and weaning plans, is personalised accordingly. ${ }^{7}$ In the paediatric intensive care field, automation of image analysis has been reported to identify pneumonia infiltrates correctly from healthy lungs with more than $90 \%$ sensitivity and $100 \%$ specificity when lung ultrasound images were processed through a neural network algorithm. ${ }^{8}$

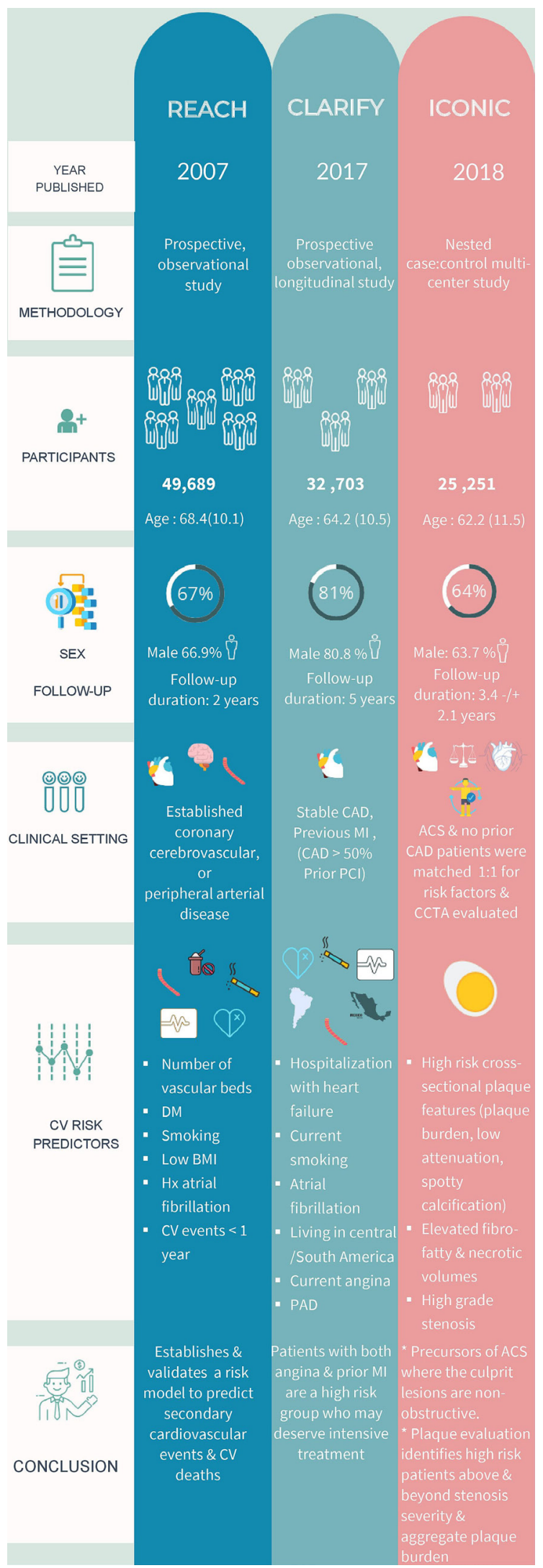

Figure 2 Summary of the most relevant trials reporting patterns of atherosclerosis. ACS, acute coronary syndrome; CAD, coronary artery disease; CCTA; cardiovascular computed tomography angiogram; CV, cardiovascular; MI, myocardial infarction; PAD, peripheral arterial disease; PCl, percutaneous coronary intervention. 
As mentioned previously, machine-assisted advances have many clinical implications in critical inpatients and stable outpatients. For example, the clinician can implement intensive prevention with statin therapy or proprotein convertase subtilisin/kexin type 9 inhibitors. Moreover, they serve as a tool to detect weaknesses in currently instated prevention programmes requiring improvement. Finally, they are a gateway to new research that can cross-reference risk factors, identify new risk factors and report the efficacy of preventive therapies in target populations. The Multi-Ethnic Study of Atherosclerosis has unequivocally revealed the ethnic differences concerning coronary artery calcium scoring (CACS). ${ }^{9}$ Eng et al previously reported the utility of ML in automating CACS from routine non-gated chest CT scans, thus allowing screening of a larger population than what individual clinics or practitioners can evaluate. ${ }^{10}$ $\mathrm{AI}$ and ML will enable healthcare systems to accurately screen patients at risk, adopt new prevention strategies, and refine existing ones tailored to specifically targeted populations, whether by age, ethnicity or geography. Eventually, they may generate new and more jobs in public health, prevention and research in many areas of medicine.

\section{Twitter Yasmin Hanfi @Jazzminem2008 and Mirvat Alasnag @mirvatalasnag}

Contributors All authors contributed equally to the preparation, writing and review of this article.

Funding The authors have not declared a specific grant for this research from any funding agency in the public, commercial or not-for-profit sectors.

Competing interests None declared.

Patient consent for publication Not applicable.

Ethics approval This study does not involve human participants.

Provenance and peer review Commissioned; internally peer reviewed.
Open access This is an open access article distributed in accordance with the Creative Commons Attribution Non Commercial (CC BY-NC 4.0) license, which permits others to distribute, remix, adapt, build upon this work non-commercially, and license their derivative works on different terms, provided the original work is properly cited, appropriate credit is given, any changes made indicated, and the use is non-commercial. See: http://creativecommons.org/licenses/by-nc/4.0/.

ORCID iDs

Yasmin Hanfi http://orcid.org/0000-0002-0354-1641

Mirvat Alasnag http://orcid.org/0000-0002-8714-0334

\section{REFERENCES}

1 Sarraju A, Ward A, Chung S, et al. Machine learning approaches improve risk stratification for secondary cardiovascular disease prevention in multiethnic patients. Open Heart 2021;8:e001802.

2 Ohman EM, Bhatt DL, Steg PG, et al. The reduction of atherothrombosis for continued health (reach) registry: an international, prospective, observational investigation in subjects at risk for atherothrombotic events-study design. Am Heart $J$ 2006;151:786.e1-786.e10.

3 Zafeiropoulos S, Farmakis I, Kartas A, et al. Risk for recurrent cardiovascular events and expected risk reduction with optimal treatment 1 year after an acute coronary syndrome. Am J Cardiol 2020;133:7-14.

4 Jonas R, Earls J, Marques $\mathrm{H}$, et al. Relationship of age, atherosclerosis and angiographic stenosis using artificial intelligence. Open Heart 2021;8:e001832.

5 Rizvi A, Hartaigh Bríain Ó, Knaapen P, et al. Rationale and design of the CREDENCE trial: computed tomographic evaluation of atherosclerotic determinants of myocardial ischemia. BMC Cardiovasc Disord 2016;16:190.

6 D'Costa A, Zatale A. Al and the cardiologist: when mind, heart and machine unite. Open Heart 2021;8:e001874.

7 Mathur P, Burns ML. Artificial intelligence in critical care. Int Anesthesiol Clin 2019;57:89-102.

8 Correa M, Zimic M, Barrientos F, et al. Automatic classification of pediatric pneumonia based on lung ultrasound pattern recognition. PLoS One 2018;13:e0206410-3.

9 Bild DE, Detrano R, Peterson D, et al. Ethnic differences in coronary calcification: the multi-ethnic study of atherosclerosis (MESA). Circulation 2005;111:1313-20.

10 Eng D, Chute C, Khandwala N, et al. Automated coronary calcium scoring using deep learning with multicenter external validation. NPJ Digit Med 2021;4:88. 